\title{
Transport Problem Identified
}

National Cancer Institute

\section{Source}

National Cancer Institute. Transport Problem Identified. NCI Thesaurus. Code C92107.

Problems traced to how the device was transported e.g. temperature of shipping compartment or method of transportation. 